
Motrivivência v. 27,
n. 46 ,
p. 53-68,
dezembro/2015

\title{
O PIBID E O PERCURSO FORMATIVO DE PROFESSORES DE EDUCAÇÃO FÍSICA
}

\author{
Daniela de Moura Clates' \\ Maria Cecília Camargo Günther
}

\section{RESUMO}

Esse artigo é resultado de uma investigação que teve como foco a repercussão das experiências acumuladas no PIBID sobre o percurso formativo de egressos do curso de Educação Física - Licenciatura do CEFD/UFSM. Trata-se de um estudo de caso descritivo, de corte qualitativo. O estudo foi desenvolvido através de revisão de literatura e entrevistas biográficas (semiestruturadas). Foram tomadas como foco de análise as experiências sociocorporais, o processo de escolha profissional e as experiências formativas vividas na graduação junto ao PIBID. Assim, compreendeu-se que o PIBID representa um importante espaço formativo e que propicia a antecipação da experiência docente, incidindo sobre a socialização profissional e construção da identidade docente desses acadêmicos. O programa pode, no entanto, avançar no sentido de aprofundar as reflexões e formulações teóricas sobre as experiências e saberes delas originados.

Palavras-chave: PIBID/Educação Física; Experiências Formativas; Percursos Formativos

1 Aluna do curso de Especialização na área da Educação Física Escolar. UFSM, Santa Maria/Rio Grande do Sul, Brasil. E-mail: danielaclates@yahoo.com.br

2 Doutora em Ciências do Movimento Humano. Professora do Centro de Desportos e Educação Física da UFSM, Santa Maria/Rio Grande do Sul, Brasil. E-mail: mceciliacg6@hotmail.com 


\section{CONSIDERAÇÕES INICIAIS}

O período que compreende a formação acadêmica na universidade nem sempre corresponde a um envolvimento exclusivo dos estudantes com disciplinas curriculares e afazeres relacionados às mesmas. A participação em projetos de extensão, grupos de pesquisa/estudo costuma ser parte da rotina de uma parcela de estudantes universitários. Estudos realizados no Centro de Educação Física e Desportos da Universidade Federal de Santa Maria (CEFD/UFSM) atestam uma participação expressiva de estudantes nas atividades mencionadas acima e sinalizam o predomínio de acadêmicos de licenciatura, em comparação com os de bacharelado (MINUZZI; RIBEIRO; MARIN, 2011) e de outra parte, revelam a importância das experiências extensionistas no percurso formativo dos investigados e a existência de grandes limitações em relação a isso no interior do centro investigada (SANTOS JR., KRUG, 2006). Lago (2011) por sua vez, constatou um aumento expressivo de projetos de extensão do ano de 2010 para 2011 (de 39 para 56), no entanto, tal aumento não representou um acréscimo em espaços de experiências formativas que tivessem a escola como lócus de atuação. Os estudos citados, embora nem sempre sejam convergentes em suas análises, têm em comum a crítica em relação a baixa presença de projetos de extensão no interior das escolas.

Alguns estudos que temos realizado nos últimos quatro anos (DELEVATI, 2012; MATNER, 2013; LEÃES, GÜNTHER, 2014; COSTA, GÜNTHER, 2014) têm nos mostrado que uma das atividades de maior interesse por parte dos acadêmicos são as que oportunizam sua inserção/aproximação com o espaço escolar, a fim de intensificar a prática docente e constituição de uma identidade profissional através das experiências por este adquirida. Nesse sentido, o Programa Institucional de Bolsa de Iniciação à Docência (PIBID) vem se constituindo como um dos espaços privilegiados para uma aproximação com a realidade do cotidiano escolar, definido assim, portanto como objeto do estudo. O PIBID - EF, Subprojeto - "Cultura esportiva da escola", tem como objetivo criar um campo de docência na Educação Básica aos futuros educadores em formação inicial e de formação continuada aos professores já em exercício, através do desenvolvimento de práticas educacionais e da construção de estratégias educacionais inovadoras na área da educação física escolar (UFSM, 02/2009).

A existência desse subprojeto no CEFD/UFSM e o grande número de estudantes envolvidos com o mesmo, desde seu início em 2009, bem como a experiência de participação de uma das autoras e, também, a realização de estudos sobre o Programa, por parte de outra autora deste artigo, nos instigou a refletir mais cuidadosamente sobre o assunto. Em particular, buscamos entender os possíveis desdobramentos sobre o percurso formativo de acadêmicos de licenciatura que dele tomam parte. Desse modo, estabelecemos como objetivo de investigação, compreender de que modo as experiências acumuladas no PIBID ao longo do período de formação acadêmica na graduação repercutiram sobre o percurso formativo dos alunos egressos do CEFD/UFSM.

O presente artigo esta organizado em quatro partes. Esta primeira refere-se as considerações iniciais trazendo o objetivo do estudo, bem como uma breve contextualização do nosso objeto de pesquisa, o PIBID. A segunda parte se reporta a 
descrição dos procedimentos metodológicos. Na sequência, explicitamos a fundamentação teórica junto às categorias de analises de forma entrelaçada, a fim de trazer um diálogo entre entrevistados, pesquisadores e a literatura, principalmente por meio de Josso (2004), Nóvoa (1995, 2000, 2003), Figueiredo $(2008,2009)$ e Moita (1992), enfatizando a discussão sobre o tema central do estudo - experiências formativas e percurso formativo. Os títulos das seções correspondem às categorias que orientaram o processo de análise. Na parte final buscamos apresentar os principais achados do estudo, relacionar as contribuições da presente pesquisa para o debate e discussões que já vem sendo travadas na literatura sobre o tema apresentado.

\section{PROCEDIMENTOS METODOLÓGICOS}

O processo investigativo configurou-se como estudo de caso descritivo. Adotamos a entrevista biográfica como instrumento da investigação, pois ela permite ao participante retomar sua trajetória formativa através de um processo reflexivo. Participaram deste estudo seis egressos do curso de Licenciatura em Educação Física (EF) do CEFD/UFSM, que atuaram no PIBID - EF, no Subprojeto "Cultura Esportiva da Escola" por, no mínimo, dois semestres.

Foram utilizadas entrevistas semiestruturadas, de caráter biográfico, nas quais, segundo Bolívar (2002), o entrevistado narra sua vida profissional ou familiar de modo que o pesquisador o leve a reorganizar os fatos citados e articule uma relação entre eles. Nesse processo, o entrevistado organiza suas experiências através de suas memórias reorganizando a trajetória percorrida, dando sentido a sua formação (ld, ibd.).
Assim, a entrevista biográfica apresenta um caráter formador, pois ao olhar para si, o entrevistado, pode vir a despertar etapas de sua formação que antes não haviam sido consideradas importantes. O entrevistado, narrador de sua própria história, conta suas experiências de vida, e ao analisá-las despontam o que foi aprendido e construído em termos de saberes, fazeres e conhecimentos (JOSSO, 2004). Esse fato pode ser constatado durante a realização das entrevistas, através da expressão facial e gestual que os entrevistados demonstram ao relatar suas experiências e, de certo modo, as revivendo.

\section{Percursos formativos - experiências na formação inicial}

O uso do termo percurso é intencional, acentuando o caráter processual da formação, já usado por outros autores (MOITA, 1992; NÓVOA, 2000). Nesse caso, o foco dirige-se ao período que compreende a formação acadêmica. Ainda que todos os acadêmicos cumpram o mesmo currículo, o fazem por caminhos distintos, agregando aprendizagens e experiências a partir da participação em diferentes programas, projetos e laboratórios que envolvem pesquisa, ensino ou extensão, de acordo com seus interesses individuais. O próprio currículo formal (disciplinas) é vivido de forma a levar cada estudante a elaborar aprendizagens distintas em um processo que é, ao mesmo tempo, social e subjetivo.

A opção por investigar egressos do PIBID, assenta-se no fato de que esse programa possibilita ao acadêmico a experiência precoce na docência, constituindo-se em um importante espaço para a reflexão sobre 
o exercício dessa docência. Conforme Freire (1996), este é um momento fundamental para a reflexão crítica sobre a prática.

O ganho principal obtido através de tais experiências reside no salto qualitativo para além da prática em si, gerando a construção de um saber pedagógico sistematicamente fundamentado (GHEDIN, 2002). Conforme analisado nas entrevistas, a participação no grupo de estudos teve um papel de grande importância na formação profissional, ao possibilitar a reflexão sobre as ações desenvolvidas nas escolas, através de leituras dirigidas e troca de experiências com os membros do grupo - acrescentando-lhes aprendizagens. No entanto, isso foi relatado por alguns dos egressos que estiveram presente no início da efetivação do PIBID, mas que no seu decorrer se depararam com a perda do sentido das reuniões. Os egressos que estiveram presentes ao final da execução do subprojeto investigado relataram que as reuniões do grupo passaram a centralizar assuntos burocráticos em detrimento das reflexões e discussões sobre o que estava acontecendo nas escolas. Assim, observamos que não há uma linearidade nas experiências do PIBID, dependendo, em parte, da constituição do grupo para que se consiga alcançar um dos objetivos do programa - a articulação entre teoria e prática.

"[...] no grupo de estudo a gente tinha textos com determinados temas e daí cada grupo, que eram as escolas, apresentava os textos que eram ótimos. Pra mim contribuíram bastante." (Professora Bruna) $)^{3}$
"[...] o grupo de estudo não abordava temas específicos, discutíamos os problemas da escola e, muitas vezes, nem isso. Tentava-se na época tratar das abordagens, mas não foi tratado. [...] o PIBID em si não discutia questões de fundo eram mais questões práticas e técnicas [...] na verdade a finalidade do grupo era de desabafo - como iríamos fazer para que os alunos nos ouvissem e, então, um citava sua experiência e outro a dele. Não era um grupo de estudos cientifico, mas sim de troca de experiências, diferente dos outros grupos que eu já tinha participado." (Professor Flávio)

"[...] éramos um grupo de estudo, mas a gente não estudava, pelo menos não na minha época. [...] a gente não estudava nada da escola, tínhamos aquela experiência prática, mas não estudávamos sobre a prática. [...] eu acho que eu ganhei muito nas experiências com os colegas, pois nos encontrávamos na escola e o tempo que tínhamos livre a gente sentava e conversava sobre a nossa prática e isso foi relevante, porque nas reuniões, que eram uma vez por semana, o professor chegava e passava os informes - eram reuniões informativas, só que para mim isso não era suficiente. Acho que, ao menos, poderia ter sido falado nas reuniões sobre as experiências na escola." (Professora Carla)

Podemos observar que o grupo de estudos do PIBID tinha características 
diferentes dos demais grupos existentes no CEFD/UFSM, conforme relatado pelo professor Flávio. Aliado a isto, o grupo também adquiriu características diferentes no decorrer de sua existência, como observamos nas falas dos entrevistados acima. Uma característica muito forte do grupo foi a troca de experiências com os colegas, agregando aprendizagens aos egressos e colaborando na formação profissional.

O que agrega o caráter formador à experiência é a geração de aprendizagens que, simbolizando condutas, pensamentos e um saber-fazer, caracterizam identidades e subjetividades. Tal processo oportuniza a atribuição de sentido ao vivido de forma simbólica e apresenta elementos proveitosos à vivência cotidiana (JOSSO, 2004).

Figueiredo (2008), fundamentada em Dubet (1994), remete ao caráter social da experiência, como uma maneira de construção da realidade. Através de uma atividade cognitiva é possível elaborar o vivido e a realidade. Para a autora, a noção de experiência social é também corporal, a qual pode ser sintetizada através do termo experiências sociocorporais (grifo nosso). Estas experiências ocupam lugar importante, mas por vezes, "perverso", nos processos de formação inicial para o ensino da Educação Física, com influência nos currículos de formação; na prática pedagógica cotidiana, com influência no ensino dos conteúdos; e na formação e transformação de identidades, com influência no tornar-se professor (FIGUEIREDO, 2009, p. 4). A referida autora explica que as experiências sociocorporais, contribuem para a construção de um conjunto de representações sobre a futura profissão e marcam a relação com os conhecimentos elaborados durante a graduação.
O professor Flávio relata na entrevista suas experiências corporais do passado, relacionadas às brincadeiras de quando criança, com seus primos, vizinhos e amigos em frente à sua casa. Suas aulas de Educação Física foram ministradas, em algumas ocasiões, por professores de outras disciplinas, nas quais ele faz um apanhado das aulas dos anos inicias, do ensino fundamental até o ensino médio, onde eram desenvolvidas atividades variadas, como: jogos populares, esportes (vôlei, futebol, futsal e caçador), ginástica, atletismo (salto em distância, salto em altura), atividades que envolviam a natureza e outras visando as olimpíadas rurais (serrar madeira, sacar milho), pois morava e estudava na zona rural até ingressar no ensino médio. Nos anos finais de estudo, as aulas foram voltadas mais para esportes e alguns trabalhos que não tinham ligação com a Educação Física. Essas experiências foram relatadas com uma riqueza tão grande de detalhes, que foi possível nos transportarmos para aquela época e perceber a importância que esses acontecimentos tiveram em sua vida.

"[...] eu não queria ser professor de outra disciplina, pois achava monótono ser um professor que ficava sentado em frente a uma turma, por exemplo, um professor de geografia ou de outra disciplina. Eu acreditava que fazendo educação física seria mais dinâmico e eu não via outras opções na lista de cursos do vestibular, nenhum se encaixava com o que eu queria. Mas a educação física talvez com essa questão de já ter vivenciado "coisas" isso me prendeu." (Professor Flávio)

Desta forma, as experiências vividas no período anterior ao ingresso na graduação podem ser consideradas como o início 
do processo de formação do professor, visto que ao ingressarem no curso de Educação Física os acadêmicos já têm uma noção do que é ser professor. Esses saberes são absorvidos a partir das experiências com os professores durante o período escolar ou com as experiências recorrentes das relações sociais fora da escola e que podem vir a influenciar a escolha profissional e, também, a prática dos futuros professores. Isso fica evidente ao analisar a fala dos entrevistados, pois, independente do ambiente em que as experiências corporais se deram elas foram marcantes e de importância quase que fundamental para a escolha da profissão e atuação profissional. Sendo essas práticas positivas ou negativas motivaram a escolha profissional mesmo que para modificar a realidade vivenciada, para isso citaremos a transcrição da fala de alguns dos entrevistados:

"[...] eu queria ser uma professora diferente da que tive, essa foi a maior motivação. (...) porque largar uma bola pro aluno, (...) não precisa de um professor pra fazer isso, qualquer tia da escola entrega a bola, o professor não precisa estar lá para entregar a bola." (Professora Carla)

"As experiências que tive na educação básica com certeza influenciaram na minha escolha profissional, pois, para mim, a professora de Educação Física era a melhor professora que tinha na escola, e não só porque oferecia uma prática que eu gostava, mas também, porque a gente viajava junto e podia conversar de tudo com ela. A gente olhava pra ela e achava ela o máximo, todo mundo gostava dela então eu queria ser assim, sabe, eu queria ser como ela." (Professora Bruna)
"Eu sempre tive bons professores e acho que isso é o que me influenciou, minha escola era pequena e os professores de Educação Física eram os melhores professores da escola, os mais queridos, os mais atenciosos, davam as melhores aulas. [...] acredito que esses bons professores que 'plantara' essa sementinha 'pra mim' cursar educação física. (sic)" (Professor Artur)

"Eu me inspirava muito nos meus professores, achava legal, na época, ser professora de Educação Física, era dinâmico, a gente conversava e as aulas eram ao ar livre, no pátio. Esse era o ambiente de trabalho que eu gostaria frequentar futuramente." (Professora Ana)

Na mesma direção, Moita (1992, p. 115) afirma que nenhum processo formativo se desenvolve desconectado da concretude da vida, por conseguinte, "ter acesso ao modo como cada pessoa se forma é ter em conta a singularidade da história e, sobretudo, o modo singular como age, reage e interage com os seus contextos". Conforme a autora, entender como acontece o processo formativo é conhecer a história de vida do sujeito, considerando a dinâmica na qual esta se construiu, formando-se e transformando-se. Tal processo constitui-se através de uma relação dialética social e objetiva na qual, ambos se influenciam mutuamente.

Retomamos Josso (2004) que menciona a experiência como sendo antes a vivência que tem intensidade particular, e que apenas atingirá a condição de experiência a partir do momento em que se realizar um trabalho reflexivo sobre o que se passou e sobre o que foi observado, percebido e sentido. Para ela, a experiência formadora 
[...] é uma aprendizagem que articula, hierarquicamente: saber-fazer e conhecimentos, funcionalidade e significação, técnicas e valores num espaço-tempo que oferece a cada um a oportunidade de uma presença para si e para a situação, por meio da mobilização de uma pluralidade de registros (JOSSO, 2004, p. 39)

Diante disso, podemos notar que a discussão e reflexão feita conjuntamente no grupo durante as reuniões do PIBID, conforme relatado, a respeito da prática realizada nas escolas, bem como em relação a conteúdos abordados em aula e nas próprias reuniões ${ }^{4}$ possui um caráter formador, pois esse espaço gera um momento reflexivo passível de propostas para uma (re)construção da pratica pedagógica experienciada.

"Com o PIBID pude colocar em prática aquilo que eu tinha na teoria e contribuir com meus colegas quanto as discussões teóricas em função do grupo de estudos que tinha no PIBID. Aprendi muito com o programa e falo até hoje [...]que aquele foi um momento muito importante, pois me achei quanto professora de Educação Física." (Professora Paula)

É relevante para o processo formativo a experiência que resulta em aprendizagens que incluem sua formulação teórica e simbolização (JOSSO, 2004) e são exatamente essas experiências que nos interessam nesse estudo.

\section{O PIBID como experiência formadora}

A formação inicial deve contemplar "os conhecimentos científicos e pedagógicos e as competências necessárias para enfrentar adequadamente a carreira docente" (CARREIRO DA COSTA, 1996, p.10). Tais conhecimentos devem, de acordo com o Projeto Pedagógico do Curso de EF (Licenciatura) formar professores capazes de:

- Desenvolver ações teórico-práticas em que os conhecimentos e saberes acadêmicos contribuam na formação do ser humano em sua totalidade;

- Possibilitar uma formação político-social, dentro de uma abordagem histórico-crítica, em diferentes manifestações da cultura corporal, compromissada com a educação emancipatória;

- Possibilitar uma formação técnico-profissional visando o aperfeiçoamento de habilidades, capacidades e competências necessárias ao exercício profissional/docente (UFSM, 2005).

Esse processo formativo prevê a inserção no contexto escolar de acordo com as práticas curriculares distribuídas ao longo do curso, culminando com os estágios curriculares. Recentemente, através de ação conjunta do Ministério da Educação (MEC), por intermédio da Secretaria de Educação Superior (SESu), da Fundação Coordenação de Aperfeiçoamento de Pessoal de Nível Superior (CAPES) e do Fundo Nacional de Desenvolvimento da Educação (FNDE), instituiu o PIBID, com finalidade fomentar a iniciação à docência contribuindo para o aperfeiçoamento da formação de docentes

4 O Subprojeto investigado realizava reuniões semanais para estudo, planejamento e discussões sobre as ações desenvolvidas nas escolas. 
em nível superior e para a melhoria da qualidade da educação básica pública brasileira (BRASIL, 2013).

A iniciativa expressa a intenção de uma ação que aproxime Universidade e Escola, tomando a formação (inicial e continuada) como eixo orientador das ações que favoreçam a inserção precoce de futuros professores, propiciando-lhes experiências concretas de ensino. Por outro lado, expressa uma valorização dos professores como co-formadores na preparação para o magistério. De modo geral, o programa foi criado para, através da melhoria do processo formativo, elevar a qualidade do ensino na Educação Básica ${ }^{5}$.

No sentido de qualificar a formação dos acadêmicos do curso de licenciatura em EF, e em conformidade com os objetivos propostos pela CAPES, foi implantado no CEFD/UFSM o PIBID - EF, Subprojeto - "Cultura Esportiva da Escola" no ano de 2009. O programa contou, desde seu início, com uma estrutura e rede de apoio constituída pelos professores do curso de graduação, professores da escola, orientador do subprojeto, alunos da escola, comunidade escolar e o suporte de equipamentos e materiais diversos (UFSM, 2009).

Estudos anteriores (DELEVATI, 2012; MATTNER, 2012) atestam que os estágios são insuficientes para que os acadêmicos possam, efetivamente, conhecer a realidade escolar e, em contrapartida, destacam a importância da participação no PIBID em seu processo formativo, exatamente no que diz respeito a experienciar a complexidade do cotidiano da escola. Isso também fica evidente nesse estudo, em que os entrevistados relatam os estágios como insuficientes por possibilitar poucas horas de práticas e não haver uma reflexão sobre as mesmas.

"[...] o curso, hoje eu consigo ver com mais clareza, tem muito separado as disciplinas teóricas das práticas, pois até $o 5^{\circ}$ semestre 'tu só tem' teoria e as práticas só começam a partir desse semestre, então quando tu começa os estágios nem lembra direito qual abordagem que deve usar e o que são abordagens. O PIBID me proporcionou isso, pois no grupo de estudo após irmos para prática a gente discutia e tentava pesquisar [...] debatíamos com os colegas quais eram os problemas que enfrentávamos com os alunos e víamos na prática quais os problemas que as escolas tinham e a gente levava esses problemas para discutir e planejar, coisa que nos meus estágios foram muito superficiais e o PIBID me ajudou muito nessa questão - (ação/reflexão/ação)." (Professora Ana)

"[...] no estágio tu tens 20 horas, tu tens que planejar 20 aulas, e só tem uma turma, no PIBID eu tinha alunos do $4^{\circ}$ ao $9^{\circ}$ ano $[. .$.$] tu tens que planejar$ aula para o semestre inteiro. No PIBID eu dava aula numa escola da periferia onde os alunos tinham dificuldades, a realidade deles era muito diferente da realidade de uma escola de centro de onde eu fiz os meus estágios, [...] no PIBID, eram muitos alunos, já nos estágios eu tinha 20 alunos no PIBID tu tens 40/50 alunos pra um professor num espaço aberto da comunidade [...] então era muito diferente, até o planejamento, pois tu tinhas que sentar e planejar realmente, no estágio tu planeja 20 aulas e tá pronto, 20 aulas agente dava por semana quase no PIBID a gente 
dava 12 aulas por semana então era muito diferente." (Professora Carla)

"[...] a oportunidade de participar do PIBID me levou para a escola três vezes por semana, acho que isso foi muito importante, isso me ajudou bastante a viver mais a escola. Então, a partir do momento que eu entrei no programa eu comecei a me identificar bem mais com a minha profissão, porque o estágio é muito pouco tempo, tu não tem tempo de compreender como é realmente a realidade dessa escola e o PIBID foi bem importante pra mim." (Professor Artur)

Nesse sentido, as experiências pré-profissionais ${ }^{6}$ e profissionais estiveram presentes de forma construtiva nas narrativas, como sendo fundamentais para afirmação na profissão, representado um momento importante em suas vidas, os fazendo compreender a importância da inserção em projetos de extensão.

"Entrei no curso achando que ia aprender basicamente esportes, pois foi o que eu tive na minha formação da educação básica. Mas com o passar do tempo eu vi que não era isso ser professor (...), no decorrer do curso eu fui me envolvendo com projetos de extensão e mudei minha visão do que é ser professor." (Professora Ana)

“(...) a gente sempre tem aquela fase de crise, eu vou largar o curso, vou fazer outra coisa, isso não compensa, e quando entrei no PIBID eu atestei que era isso que eu queria para minha vida, era isso que eu queria fazer. Se eu não tivesse entrado, com certeza, não teria me encontrado nessa profissão. (...) eu tive contato com a vida da escola não apenas com os alunos, mas também com funcionários, professores e direção, participei da vida do cotidiano da escola." (Professora Paula)

O PIBID permite um maior conhecimento acerca da realidade da futura profissão e das falhas do processo de formação e parece contribuir para o percurso formativo com a antecipação da socialização docente, agregando à formação a busca "por ouvir o lugar desses processos e sua articulação na dinâmica dessas vidas" (JOSSO, 2004, p.38). Por conseguinte, visando à assimilação de teorias, métodos de intervenção e processos reflexivos ligados às ações de mudanças na formação de professores e da educação, o programa oferece elementos para a base, à docência durante o percurso formativo, ampliando o olhar para diferentes elementos que constituem a realidade da educação, do trabalho e formação de professores. Ao compreender a realidade do campo escolar, percebe-se que o ensino superior e a educação básica não representam uma dicotomia, e sim lugares de práticas formativas e docentes.

A relação entre esses espaços se evidencia nas entrevistas, nas quais os pesquisados narram a participação em projetos como forma de complementação para o currículo da graduação, pois torna possível elaborar conhecimentos necessários para a atuação docente com base em situações concretas. Assim, podemos dizer que o programa traz um entendimento mais consistente da docência, ao introduzir o

6 Estas experiências denominadas por Silva e Bracht (2005) como experiências precoces, podem ter um papel importante na elaboração de representações esclarecedoras sobre a prática docente e sobre si mesmos. 
acadêmico na escola e the oportunizar o conhecimento sobre as rotinas escolares para além da aula de EF.

O curso de EF licenciatura do CEFD/ UFSM, por sua vez, não parece assegurar a indissociabilidade entre teoria e prática no trato com os diferentes conhecimentos, ao contrário, frequentemente, sequer existe uma articulação entre a teoria das salas de aula e a prática docente. Nessa direção, Nóvoa (2003) nos faz refletir quanto às experiências vividas no espaço escolar, ao afirmar que:

É evidente que a Universidade tem um papel importante a desempenhar na formação de professores. Por razões de prestígio, de sustentação científica, de produção cultural. Mas a bagagem essencial de um professor adquire-se na escola, através da experiência e da reflexão sobre a experiência. Esta reflexão não surge do nada, por uma espécie de geração espontânea. Tem regras e métodos próprios (Nóvoa, 2003, p. 5).

O ensino superior público é almejado por um número muito grande de estudantes e, em consequência disso, há necessidade de se expandir a educação superior, mas devendo-se corresponder consecutivamente com a elevação da qualidade da formação, entrelaçando teoria e prática, educação e vida (FREITAS, 2012). Partindo dessa compreensão que a formação inicial vai além da sala de aula dos cursos de graduação e que o envolvimento do acadêmico em projetos incide na formação, no processo de produção do conhecimento e por consequência, na sua futura atuação profissional, entendemos que a atuação do projeto devesse ser mais ampla, atingindo um número maior de futuros professores.
Esta iniciativa, portanto, daria igual oportunidade aos estudantes de licenciaturas de atuar na docência precoce, podendo assim, transformar sua trajetória acadêmica de mero cumprimento curricular, em oportunidade de construção de sua identidade.

\section{Ser professor - experiências da formação}

A constituição da identidade profissional se inicia antes mesmo do ingresso no curso superior, a partir das trajetórias individuais, durante o processo de formação e de como vivemos a formação, entrando em contato consigo mesmo. Adquire-se, desse modo, saberes que interferem na percepção acerca da profissão, nos remetendo a realidade. A formação passa a ser uma parte constituinte da identidade. Da mesma forma, Figueiredo e Morais (2013, p.56) trazem a identidade como elemento que vai se formando e "transformando ao longo da vida do indivíduo, num processo descontínuo de construção individual e coletiva no meio social".

As identidades individuais e sociais são construídas a partir de narrativas, de histórias que contamos e relembramos sobre nós e sobre outras pessoas que fizeram parte de nossas vidas, possibilitando assim um conhecimento sobre quem somos, estando a noção de identidade associada à ideia de memória. Figueiredo (2009, p.2) aponta suas lembranças como forma para "construir, reconstruir e registrar" suas experiências de vida.

Os acontecimentos da infância, contudo, são levados para vida toda, na qual estas histórias compõem a formação ao longo de nossas vidas. Assim, a construção da identidade profissional não deve ser 
considerada somente a partir de seus conhecimentos adquiridos ao longo da graduação, mas também através de toda uma história de vida, experiências familiares, sociais, culturais e a inserção na carreira docente ainda que precoce, com seus desafios, conflitos, anseios e dificuldades enfrentadas.

Conforme ressalta Nóvoa (1995, p. 16),

\begin{abstract}
A identidade não é um dado adquirido, não é uma propriedade, não é um produto. A identidade é um lugar de lutas e de conflitos, é um espaço de construção de maneiras de ser e de estar na profissão. Por isso, é mais adequado falar em processo identitário, realçando a mescla dinâmica que caracteriza a maneira como cada um se sente e se diz professor.
\end{abstract}

Com base nos argumentos acima, o processo identitário que constitui o profissional é de suma importância, seja ele concebido no espaço familiar, acadêmico e escolar, durante atuação docente, pois, assim, através das experiências construídas nesses espaços é que se adquirem identidades nos variados momentos de sua vida que se completam para a formação da identidade profissional.

Nóvoa (2000, p.16) lembra que cada professor "tem o seu modo próprio de organizar as aulas, de se movimentar na sala, de dirigir-se aos alunos, de utilizar os meios pedagógicos, um modo que constitui uma segunda pele profissional" e, com o professor de EF isso vai mais além, ele se diferencia ainda mais de outros professores de outras áreas pelo local e a forma que suas aulas acontecem. A maioria dos egressos traz isso bem definido em suas experiências no PIBID, por terem autonomia em suas aulas, para escolha de conteúdo, e a forma de ministrá-las. O Professor Flávio, em oposição a isso, relata que na época teve que se adequar as exigências da escola e não teve autonomia para elaboração de suas aulas, sendo várias vezes reprimido por professores e pela direção da escola, na forma que conduzia suas aulas. Os estágios, para todos os entrevistados, não deram liberdade para escolha e modo de ministrar suas aulas, no qual, o estagiário teve que assumir uma identidade já constituída pela escola e professor.

As experiências durante a formação inicial se configuram como momentos de fundamental importância no processo de construção de identidades e saberes docentes (SILVA; BRACHT, 2005). A partir das experiências precoces, durante a participação no PIBID, os egressos conseguem se "encontrar quanto professor" das condições previstas no currículo da graduação que não oportunizam uma imersão no universo da escola de forma a captar toda a sua complexidade.

"[...] o projeto, ele me ajudou a me encontrar enquanto professor. Quando bolsista, nós tínhamos responsabilidades, eu tinha responsabilidade com a escola, com a tua turma, com o grupo que trabalhava comigo, 'acho ai' o PIBID foi bem importante, 'pra mim' ele me trouxe um amadurecimento muito, muito grande." (Professor Artur)

"[...] eu já tinha passado pelos estágios e eu não tinha conseguido me encontrar. E, quando entrei no PIBID, foi um marco, eu tive esse contato com a vida

7 Fala expressa por um dos entrevistados. 
da escola não só com os alunos, que eu não era só a estagiaria, eu era a professora da escola, eu tinha o contato com os funcionários, com professoras, com a direção, tem aquela coisa de ficar com as crianças na hora do recreio, participar da vida do cotidiano da escola, acho que é isso que te estabelece na escola enquanto professor e foi o que o PIBID me proporcionou [...] essa experiência é um aprendizado muito maior que o estágio, então eu acho que o PIBID conta muito mais do que o estágio pra formação, pelo menos pra minha formação foi assim." (Professora Paula)

Ao referir-se a formação, Moita (1992, p.115) menciona a não dicotomização entre profissão e vida. Nas palavras da autora "ninguém se forma no vazio. Formar-se supõe troca, experiência, interações sociais, aprendizagens, um sem fim de relações". Assim, o processo de formação está relacionado com a construção de identidade do indivíduo.

Desse modo, a experiência formadora para Josso (2004), assim como, para Figueiredo (2009) e Moita (1992) parece estar em profunda relação com a constituição de identidade que acompanha o percurso formativo, não como um fato, mas um processo contínuo. Trata-se de uma concepção de formação que vai além de "uma atividade de aprendizagem situada em tempos e espaços limitados e preciosos, mas também, como a ação vital de construção de si próprio" (MOITA, 1992, p.114).

Assim, o percurso formativo não faz menção apenas à vida acadêmica, existem questões de experiências anteriores atreladas a isso, compondo a formação. Bem como o processo de socialização docente que "não se circunscreve, portanto, à vida escolar, outros centros de interesse, ocupacional ou não, intervêm nesse percurso" (CARVALHO, 1996, p.39).

A socialização de professores procede do contato mais direto com a escola, na qual se passa a viver a instituição como um todo. Igualmente, o PIBID, tem essa função social com os acadêmicos de inseri-los na escola de forma a se sentirem reais professores, convivendo com os problemas, não apenas das turmas as quais ministram aulas, mas da escola de um modo geral.

\section{CONSIDERAÇÕES FINAIS}

A reflexão sobre os acontecimentos passados, que tenham se configurado desde a infância, perpassando o percurso formativo dos egressos, chegando as ações atuais, não foi tarefa simples para muitos dos entrevistados. No entanto, ao narrar suas experiências, sejam elas pré-profissionais ou profissionais, representou para a maioria dos entrevistados, uma experiência de descoberta de si mesmo. Ao relatarem suas vivências, os professores vivenciaram uma retrospectiva de suas experiências formadoras. As narrativas foram detalhadas, com riqueza de significados para cada ação, como suas expectativas, certezas e incertezas, as quais estiveram presentes durante suas formações.

As experiências sociocorporais vividas anteriormente à graduação influenciaram na escolha pelo curso de Educação Física, para a maioria dos entrevistados. Entretanto, as lacunas de conhecimento sobre o currículo e objetivos da Licenciatura na área, se transformaram em decepção para alguns dos entrevistados, mas que, com o decorrer da graduação e inserção em projetos, conseguiram superar e se encontrar na 
condição de professor. Em relação a isso, o estudo sinaliza a necessidade de uma atenção maior para a relação entre os projetos e o currículo, de modo a criar articulação entre esses diferentes espaços formativos. No momento parece predominar uma relação na qual os projetos complementam o currículo sem que haja um diálogo entre esses espaços.

As experiências formadoras vivenciadas no PIBID, portanto, se configuraram como importantes contribuições para a formação dos egressos, no que diz respeito às práticas pedagógicas desenvolvidas. Estas, por sua vez, influenciaram a visão de si próprios como professores no decorrer do programa, atuando como suporte nas experiências curriculares e complementando a graduação, além de se configurar como um aporte para a constituição da identidade no decorrer do percurso. Assim, há unanimidade entre os entrevistados, no entendimento que a socialização docente vivida a partir da inserção no programa interferiu de forma positiva para o enriquecimento de experiências concretas vividas na escola. No entanto, estas experiências foram marcadas por um descaso (ou pouca valorização) quanto a significações teóricas que poderiam ter sido pertinentes durante esse processo. Conforme relatos, os temas abordados além de terem sido poucos, não faziam referência ao que se necessitava para atuação.

Os relatos apresentados, em sua maioria, identificaram o PIBID como um aporte para a constituição da identidade profissional no decorrer do percurso formativo, trazendo a afirmação na profissão e o amadurecimento do acadêmico, ainda que essa identidade se configure de forma provisória e inacabada, próxima de um pro- cesso identitário que se prolongará durante percurso profissional. No entanto, apenas em um dos relatos foi possível identificar que o programa não trouxe esse amadurecimento, por não possibilitar ao acadêmico autonomia para realização de suas aulas, sendo obrigado a manter o perfil docente existente e o modelo tradicional de ensino da escola, preservando a identidade da instituição não dando oportunidade para construção própria, tendo que se apropriar de uma já existente e imposta.

Para os egressos investigados, a presença concreta no espaço escolar oportunizou a vivência nos mais variados contextos e realidades, fazendo com que se sentissem parte da escola. A partir disso, foi possível identificar nos relatos que o programa tem sido de grande importância para sua formação inicial, propiciando a esses jovens professores experiências significativas e consistentes sobre a realidade escolar. Por outro lado, o programa ainda deixa a desejar no que diz respeito a indissociabilidade entre teoria e prática, incorrendo, em algumas limitações também presentes na graduação. O que se pode apontar, a partir desse estudo é que o PIBID tem se constituído em um espaço diferenciado no que diz respeito a gerar experiências relevantes na formação de futuros professores de EF, mas pode, por outro lado, oferecer situações de aprofundamento e maior solidez em relação às elaborações teóricas que emergem desse processo.

\section{REFERÊNCIAS}

BOLIVAR, A. Profissão professor: o itinerário profissional e a construção da escola. EDUSC, 2002. ISBN 8574601454. 
BRASIL. Ministério da Educação. Programa Institucional de Bolsas de Iniciação à Docência (Pibid). 2013. Disponível em: < http://portal.mec.gov.br/index. php? ltemid $=467 \&$ id $=233$ \&option $=\mathrm{c}$ om_content\&view $=$ article $>$. Acesso em: 26/04/2013.

CARREIRO DA COSTA, F. Formação de professores: objectivos, conteúdos e estratégias. In: CARREIRO DA COSTA, F.;CARVALHO, L. M., et al (Ed.). Formação de Professores em Educação Física: concepções, investigações, prática. Faculdade de Motricidade Humana, v.5, 1996. p.9- 36.

CARVALHO, L. M. A formação inicial de professores revisitada: contributos da investigação sobre a socialização dos professores. In: COSTA, F. C.;CARVALHO, L. M., et al (Ed.). Formação de Professores em Educação Física: concepções, investigações, prática. Faculdade de Motricidade Humana, 1996. p.37 - 56. ISBN 9727350313.

COSTA, T. M.; GÜNTHER, M.C.C. PIBID/ Cultura Esportiva da Escola: o processo formativo dos estudantes de educação fisica. Políticas Educativas, Porto Alegre, v. 8, n. 1, p. 118-134, 2014.

DELEVATI, M. A presença das Abordagens Teórico-Metodológicas da Educação Física no PIBID/UFSM - Nexos com a Formação Inicial. 2012. (Trabalho de Conclusão de Curso). Universidade Federal de Santa Maria.

DUBET, F. Sociologia da Experiência. Portugal: Instituto Piaget, 1994.

FIGUEIREDO, Z. C.; MORAIS, E. A. L. Histórias de vida e de aprendizagem da docência de professores de um curso de Licenciatura em Educação Física.
Pensar a Prática, v. 16, n. 1, 2013. ISSN 1980-6183.

FIGUEIREDO, Z. C. C. Experiências sociocorporais e formação docente em educação física. Movimento (ESEF/ UFRGS), v. 14, n. 1, p. 85-110, 2008. ISSN 1982-8918.

\section{. Experiências Profissionais,} Formação e Identidades. XVI Congresso Brasileiro de Ciências do Esporte e III Congresso Internacional de Ciências do Esporte. Salvador - Bahia 2009.

FREIRE, P. Pedagogia da autonomia: saberes necessários à prática docente. São Paulo: São Paulo: Paz e Terra (Coleção Leitura), 1996.

FREITAS, H. C. L. Federalismo e formação profissional: por um sistema unitário e plural. Retratos da Escola, v. 6, n. 10, p. 211-225, 2012. ISSN 2238-4391.

GHEDIN, E. Professor reflexivo: da alienação da técnica à autonomia da crítica. In: PIMENTA, S. G. e GHEDIN, E. (Ed.). Professor reflexivo no Brasil: gênese e crítica de um conceito. São Paulo: Cortez. São Paulo: Cortez Editora, 2002. p.129-150.

JOSSO, M.C. Experiências de vida e formação. São Paulo: Cortez Editora, 2004. ISBN 9728036388.

LAGO, S. Configuração dos projetos de extensão e a formação inicial dos acadêmicos do Curso de Educação Física - Licenciatura do CEFD/UFSM. 2011. (Trabalho de Conclusão de Curso). Universidade Federal de Santa Maria.

LEÃES N. C.; GÜNTheR, M. C. C. Socialização docente experiências pré-profissionais. IV Congresso Internacional Sobre Professorado Principiante e Inserção profissional à 
Docência. Curitiba: Ed. UTFPR. Anais IV CONGREPRINCI, CD-ROM, 2014. MATTNER, C. V. A Formação Inicial em Educação Física e as Práticas Pedagógicas dos Bolsistas do PIBID/ UFSM. 2012. (Trabalho de Conclusão de Curso). Universidade Federal de Santa Maria

MINUZZI, E. D.; RIBEIRO, G. M.; MARIN, E.

$M$. A ênfase dada à formação inicial no curso de Educação Física Licenciatura do CEFD/UFSM a partir dos projetos de ensino e extensão. XVII Congresso Brasileiro de Ciências do Esporte e IV Congresso Internacional de Ciências do Esporte. Porto Alegre, RS.: Anais do XVII CONBRACE, IV CONICE, 2011.

MOITA, M. D. C. Percursos de formação e de trans-formação. In: NÓVOA, A. (Ed.). Vidas de professores. Porto: Portugal: Porto Editora, v.2, 1992. p.111-140.

NÓVOA, A. Os professores e sua formação. Lisboa, Portugal: Dom Quixote, 1995. - Os professores e as histórias da sua vida. In: NÓVOA, A. (Ed.). Vidas de professores. Porto: Portugal: Porto Editora, v.2, 2000. p.11-30. . Novas disposições dos professores. A escola como lugar da formação. Correio da educação, p. 16, 2003. Disponível em: < http://repositorio. ul.pt/bitstream/10451/685/1/21205_ ce.pdf >. Acesso em: 19/06/2013.

SANTOS JUNIOR, S. L. Extensão Universitária: contribuições à formação inicial de professores de educação física. 2000. Monografia (Especialização em Ciência do Movimento Humano). Universidade Federal de Santa Maria.

SILVA, M. S. D.; BRACHT, V. Intervenção profissional durante a formação inicial: contradições e possibilidades das experiências docentes precoces em educação física. Motrivivência, v. 17, n. 25, p. 57-76, 2005.

UFSM. Projeto Pedagógico do Curso de Educação Física Licenciatura. DESPORTOS., C. D. E. F. E. 2005.

\section{THE PIBID AND THE COURSE FORMATION OF PHYSICAL EDUCATION TEACHERS}

\section{ABSTRACT}

This article is the result of an investigation that focused on the impact of accumulated experiences in PIBID about the course formation of graduates of the course of Physical Education - Licensed from CEFD / UFSM. The methodology was characterized as descriptive case study. The research was developed through literature review and biographical interviews (semi structured). The focus of analysis were the sociocorporal experiences, the process of choice of occupation, and the experiences in graduation with the PIBID. Thus, the PIBID represented an important training area, which provides the anticipation of teaching experience, focusing on the professional socialization and the construction of teacher identity of these academics. The program can, however, move to deepen the reflections and theoretical formulations on the experiences and knowledge of them originated. 


\section{EL PIBID Y EL CURSO DE FORMACIÓN DE PROFESORES DE EDUCACIÓN FÍSICA}

\section{RESUMEN}

Este artículo es el resultado de una investigación que se centró en el impacto de las experiencias acumuladas en PIBID en el curso de formación para graduados del curso de Educación Física - Licenciatura en CEFD / UFSM. La metodología se caracterizó como estudio de caso descriptivo. El estudio se desarrolló a través de revisión bibliográfica y entrevistas biográficas (semi-estructurado). Se tomaron como el foco de las análisis las experiencias sociocorporal, el proceso de elección de carrera y las experiencias formativas en la graduación por el PIBID. Así, se entiende que el PIBID es un espacio formativo importante para la promoción de una anticipación de experiencia en la enseñanza, centrándose en la socialización profesional y la construcción de la identidad docente de estos académicos. El programa puede, sin embargo, pasar a profundizar las reflexiones y formulaciones teóricas sobre las experiencias y el conocimiento de ellos originado.

Palabras clave: PIBID/Educación Física; Experiencias Formativas; Itinerario Formativo

Recebido em: julho/2015 Aprovado em: outubro/2015 